\title{
Epidemiology, Clinical Characteristics, and Visual Outcomes of Patients with Intraocular Foreign Bodies in Southwest China: A 10-Year Review
}

\author{
Tiancong Chang ${ }^{\mathrm{a}}$ Yun Zhang ${ }^{\mathrm{a}}$ Ling Liu $^{\mathrm{a}}$ Keren Zhang $^{\mathrm{a}}$ Xinyu Zhang ${ }^{\mathrm{a}}$ \\ Miao Wang ${ }^{a}$ Yue Zeng $^{\mathrm{a}}$ Meixia Zhanga,b \\ a Macular Disease Research Laboratory, Department of Ophthalmology, West China Hospital, Sichuan

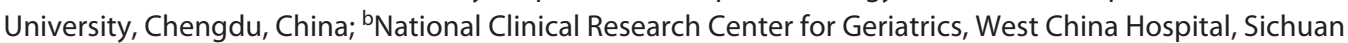 \\ University, Chengdu, China
}

\section{Keywords}

Intraocular foreign bodies · Southwest China ·

Epidemiology

\begin{abstract}
Introduction: Intraocular foreign bodies (IOFBs) are a serious subset of open-globe injury that can result in visual loss. This study analyzed the epidemiology, clinical characteristics, and visual outcomes of patients with IOFBs in Southwest China. Methods: This retrospective study comprised 1,176 patients with the primary diagnosis of IOFBs who resided in Sichuan Province over a 10-year period. All data were collected from medical records and analyzed statistically. $\boldsymbol{R} \boldsymbol{e}$ sults: The annual incidence for IOFBs was 0.14 per 100,000 (95\% confidence interval $0.12-0.16$ per 100,000 ) people in Southwest China. In that period, IOFBs accounted for $22.3 \%$ of all open-globe injuries. Working-age male patients accounted for $79.1 \%$ of all IOFBs patients and there had significant differences in age distributions between genders $(p<0.001)$. Metallic IOFBs were the most common $(74.6 \%)$ IOFB, but there were significant differences in the materials of IOFBs between adults and children of different age-groups $(p<0.001)$. At discharge, 277 (23.6\%) patients had increased
\end{abstract}

karger@karger.com www.karger.com/ore

Karger $\stackrel{\text { ' }}{5}$
(C) 2020 The Author(s)

Published by S. Karger AG, Basel

This is an Open Access article licensed under the Creative Commons Attribution-NonCommercial-4.0 International License (CC BY-NC) (http://www.karger.com/Services/OpenAccessLicense), applicable to the online version of the article only. Usage and distribution for commercial purposes requires written permission. visual acuity (VA) and 95 (8.0\%) had no light perception. Initial VA $<20 / 200$ (odds ratio [OR], 5.5; $p<0.001$ ), increasing wound size (OR, $1.3 ; p=0.004)$, IOFBs in the posterior segment (OR, 2.6; $p=0.002)$ and existing complications (traumatic cataract, endophthalmitis, retinal detachment, or retinal break) were independent risk factors for final VA $<20 / 200$. Conclusion: The incidence of IOFBs in Southwest China differed from global statistics. Adults and children had different clinical characteristics. Thus, their prevention strategies should be different.

(c) 2020 The Author(s)

Published by S. Karger AG, Basel

\section{Introduction}

Intraocular foreign bodies (IOFBs) account for 18$41 \%$ of all open-globe injuries so are a substantial public health problem worldwide $[1,2]$. IOFBs may result in a wide range of intraocular pathologies [3]. In 2008, the UK reported the current incidence and clinical characteristics of IOFBs and China reported that in 2011 [4]. However,

Tiancong Chang and Yun Zhang contributed equally.
Correspondence to:

Meixia Zhang, coretina@gmail.com 


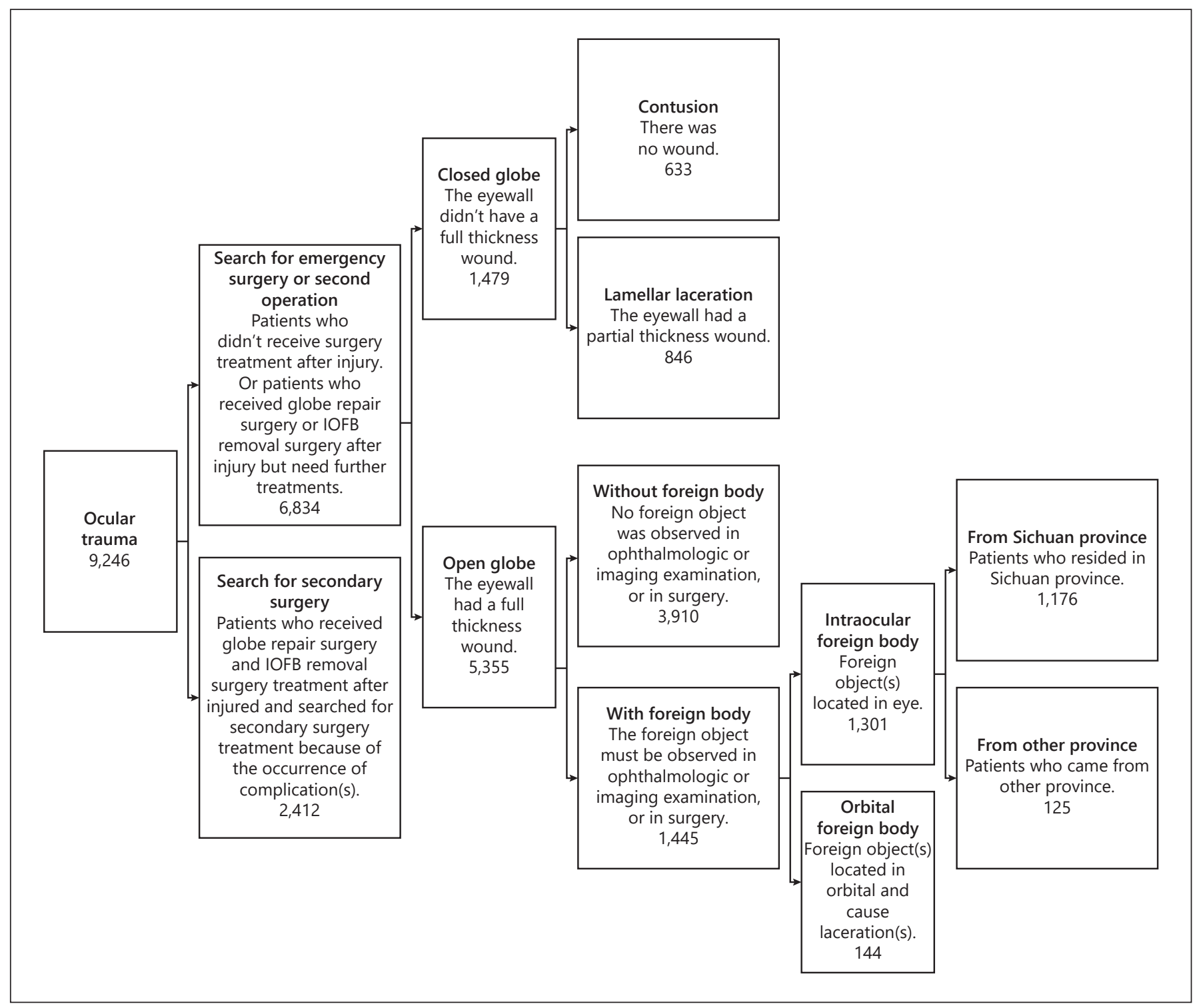

Fig. 1. Extraction methods and final number of records of patients with ocular trauma at the West China Hospital, Chengdu, Sichuan Province, between 2009 and 2018. Patients were grouped according to the type of eye injuries (based on the Birmingham Eye Trauma Terminology System [12]), injury history, and address. IOFB, intraocular foreign body.

the clinical characteristics in different districts might be heterogenous. From the whole point of view, IOFBs accounted for $28.6 \%$ of all open-globe injuries in China [4]. But in Hubei Province, which located in south central China, IOFBs accounted for $16.2 \%$ [5]. And in Hong Kong, IOFBs accounted for 16\% [6]. Of note, epidemiologic data of IOFBs in Southwest China are still unrevealed.

Besides, there were several studies describing the clinical characteristics of ocular trauma in specific popula- tion such as children [7, 8], working-age adults [9], and elderly people [10]. However, only few studies reported the clinical characteristics of IOFBs in children [11], and no study focused on the differences of clinical characteristics between adults and children. Thus, this study aimed to analyze epidemiology, clinical characteristics, and visual outcomes in patients with IOFBs in Sichuan Province, which located in Southwest China, and determine whether there were differences of characteristics among adults and children in different age-group. 
Table 1. Demographics of patients hospitalized for IOFBs

\begin{tabular}{|c|c|}
\hline Total patients & $1,176^{\mathrm{a}}$ \\
\hline \multicolumn{2}{|l|}{ Gender, $n(\%)$} \\
\hline Male & $1,099(93.5)$ \\
\hline Female & $77(6.5)$ \\
\hline \multicolumn{2}{|l|}{ Marriage status, $n(\%)$} \\
\hline Single & $181(15.4)$ \\
\hline Married & $914(77.7)$ \\
\hline Child and teenager & $78(6.6)$ \\
\hline Unknown & $3(0.3)$ \\
\hline \multicolumn{2}{|l|}{ Level of education, $n(\%)$} \\
\hline Illiteracy & $54(4.6)$ \\
\hline Literate, completed primary education & $384(32.7)$ \\
\hline Literate, completed secondary education & $497(42.3)$ \\
\hline Literate, completed higher secondary education & $91(7.7)$ \\
\hline Literate, completed college/polytechnic & $55(4.7)$ \\
\hline Toddler/preschooler & $24(2.0)$ \\
\hline Grade schooler/adolescent & $69(5.8)$ \\
\hline Unknown & $2(0.2)$ \\
\hline \multicolumn{2}{|l|}{ Occupation, $n(\%)$} \\
\hline Worker & $480(40.8)$ \\
\hline Farmer & $443(37.7)$ \\
\hline Business/teacher & $38(3.2)$ \\
\hline Student & $61(5.2)$ \\
\hline Toddler/preschooler & $24(2.0)$ \\
\hline Other & $39(3.3)$ \\
\hline Not working & $91(7.8)$ \\
\hline \multicolumn{2}{|l|}{ Location, $n(\%)$} \\
\hline Urban & $349(29.7)$ \\
\hline Rural & $827(70.3)$ \\
\hline \multicolumn{2}{|l|}{ Cause of injury, $n(\%)$} \\
\hline Work & $926(78.7)$ \\
\hline Daily life & $143(12.2)$ \\
\hline Accident & $33(2.8)$ \\
\hline Assault & $1(0.1)$ \\
\hline Firecracker or firework & $35(3.0)$ \\
\hline Other & $38(3.2)$ \\
\hline
\end{tabular}

${ }^{\text {a }}$ A total of 1,176 patients were identified in our study.
All cases of IOFBs were diagnosed according to the Birmingham Eye Trauma Terminology System $[12,13]$. A diagnosis of IOFB indicates any open-globe injury with a retained foreign object, which must be observed in ophthalmologic or imaging examination or in surgery.

The medical record system of our hospital was the source for all patient data. According to the laws of China, we classified patients $\geq 18$ years old as adults and patients $<18$ years old as children. Based on their age and study status, we divided the children into 3 groups: preschool children (0-6 years old), primary school children (7-12 years old), and secondary school children or adolescents (13-17 years old). Visual acuity (VA) was the best-corrected or pinhole VA and was converted from decimal VA to Snellen VA ratios $[14,15]$. The largest IOFB was recorded if there were multiple IOFBs in an eye. The location of the wound was divided into 3 zones according to the Ocular Trauma Classification Group: Zone I included an opening limited to the cornea, Zone II included a wound involving the anterior $5 \mathrm{~mm}$ of the sclera, and Zone III included injuries $>5 \mathrm{~mm}$ posterior to the corneoscleral [16].

Diagnosis of endophthalmitis was made based on clinical symptoms and signs before and during the surgery. The culture outcomes were not considered in the diagnosis of endophthalmitis because culturing of intraocular contents was performed in only some of the cases and the rate of positive cultures was low, even in some cases with obvious symptoms.

All data were collected into an electronic database and were cross-checked for errors. Data in this report are presented as mean \pm standard deviation for continuous variables and as frequency or percentage for categorical variables. Continuous variables were evaluated for normality, and means were compared using a 2-tailed $t$ test. Categorical variables were analyzed using a $\chi^{2}$ test. Univariate and multivariate analyses were conducted to determine the independent factors affecting visual outcome after the occurrence of an IOFB. All statistical analyses were performed using statistical software packages R (http://www.R-project.org, The R Foundation, Vienna, Austria) and EmpowerStats (http://www.empowerstats.com, X \& Y Solutions, Inc., Boston, MA, USA). A $p$ value of $<0.05$ was considered statistically significant for all tests.

\section{Results}

\section{Demographics}

The demographic characteristics are shown in Table 1. A total of 1,176 patients with IOFBs were included, accounting for $22.3 \%$ of all open-globe injuries. The mean annual incidence of hospitalization for IOFBs was estimated to be 0.14 per 100,000 (95\% confidence interval [CI] 0.12-0.16 per 100,000) people in Sichuan Province, which is located in Southwest China and is regarded as representative of this region. Figure 2 shows the detailed incidence of IOFB for each year among this 10 -year period.

Among these patients, 1,099 (93.5\%) were males and $77(6.5 \%)$ were females, yielding a male-to-female ratio of 14.3:1. The mean ( \pm standard deviation) patient ages were 
Table 2. Frequency of IOFBs by sex and age-groups

\begin{tabular}{rccll}
\hline Age-group & $\begin{array}{l}\text { Male, } \\
n(\%)\end{array}$ & $\begin{array}{l}\text { Female, } \\
n(\%)\end{array}$ & $\begin{array}{l}\text { Male-to-female } \\
\text { ratio }\end{array}$ & $p$ value \\
\hline $1-10$ & $39(3.5)$ & $13(16.9)$ & $3: 1$ & $<0.001$ \\
$11-20$ & $78(7.1)$ & $6(7.8)$ & $13: 1$ & \\
$21-30$ & $172(15.7)$ & $3(3.9)$ & $57.3: 1$ & \\
$31-40$ & $239(21.7)$ & $16(20.8)$ & $14.9: 1$ & \\
$41-50$ & $337(30.7)$ & $25(32.5)$ & $13.5: 1$ & \\
$51-60$ & $182(16.6)$ & $8(10.4)$ & $22.8: 1$ & \\
$61-70$ & $47(4.3)$ & $5(6.5)$ & $9.4: 1$ & \\
$70-80$ & $4(0.4)$ & $1(1.3)$ & $4: 1$ & \\
$80-90$ & $1(0.1)$ & $0(0.0)$ & - & \\
\hline
\end{tabular}

Table 3. Characteristics of wound and foreign bodies

\begin{tabular}{|c|c|}
\hline Variable & Characteristics \\
\hline \multicolumn{2}{|l|}{ Wound, $n(\%)$} \\
\hline \multicolumn{2}{|l|}{ Zone } \\
\hline I & $984(83.2)$ \\
\hline II & $111(9.4)$ \\
\hline III & $72(6.1)$ \\
\hline Unknown & $16(1.3)$ \\
\hline \multicolumn{2}{|l|}{ Type } \\
\hline Penetration & $1,050(88.8)$ \\
\hline Perforation & $33(2.8)$ \\
\hline Rupture & $34(2.9)$ \\
\hline Unknown & $66(5.6)$ \\
\hline Size, $\mathrm{mm}$ & $3.8 \pm 3.1$ \\
\hline \multicolumn{2}{|l|}{ Foreign bodies, $n(\%)$} \\
\hline \multicolumn{2}{|l|}{ Number } \\
\hline 1 & $1,073(94.1)$ \\
\hline 2 & $34(3.0)$ \\
\hline 3 & $12(1.1)$ \\
\hline$>3$ & $19(1.6)$ \\
\hline Unknown & $45(3.8)$ \\
\hline \multicolumn{2}{|l|}{ Location } \\
\hline Cornea & $64(5.5)$ \\
\hline Anterior chamber & $105(9.0)$ \\
\hline Sclera & $51(4.4)$ \\
\hline Lens & $99(8.5)$ \\
\hline Vitreous & $324(27.7)$ \\
\hline Retina & $515(44.1)$ \\
\hline Unknown & $11(0.9)$ \\
\hline Size, $\mathrm{mm}$ & $6.1 \pm 6.2$ \\
\hline
\end{tabular}

$39.2 \pm 14.0$ years for males and $36.2 \pm 18.4$ years for females $(p=0.38)$. The largest number of injuries occurred among patients aged $40-50$ years old, but there were significant differences in sex ratio between different agegroups $(p<0.001)$ (Table 2). The male-to-female ratio of preschool children (ages $0-6$ ) is $2.4: 1$, while that of ado-

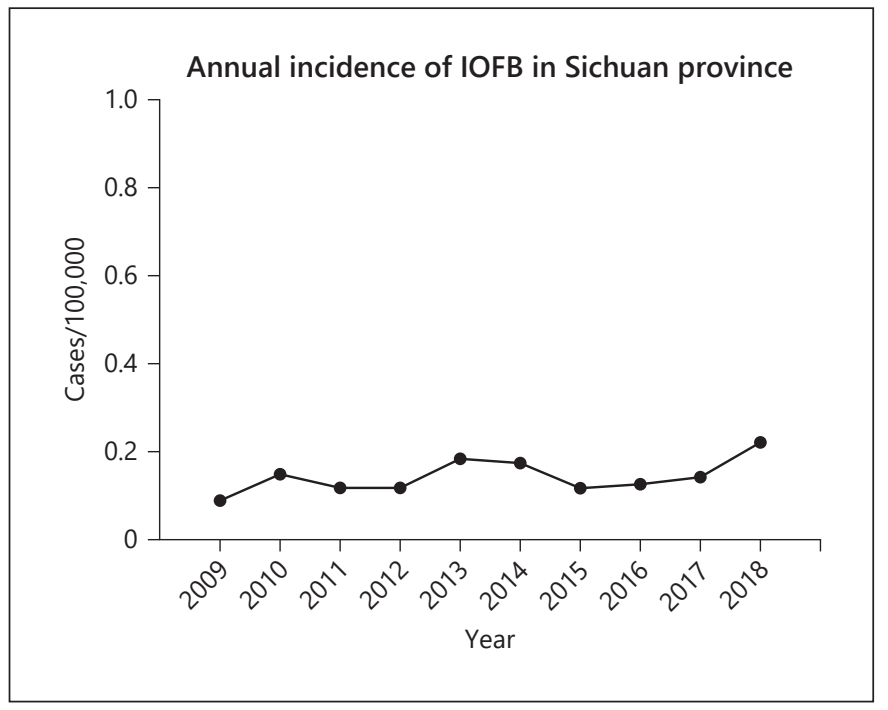

Fig. 2. The annual incidence of IOFB in Sichuan Province, Southwest China. IOFB, intraocular foreign body.

lescents is $26: 1$. The most common occupation was worker $(40.8 \%, n=480)$, followed by farmer $(37.7 \%, n=443)$, in addition, $86.5 \%$ adults with $\leq 9$ years of education (with primary and/or secondary education).

The delay in presentation of the patients, that is, between injury and arrival at the hospital, ranged from $1 \mathrm{~h}$ to 40 years. Just over half (50.3\%) of the patients presented within $24 \mathrm{~h}$ and $77.6 \%$ presented within 3 days. However, $2.0 \%$ presented more than 1 year after the trauma. The delay in presentation was not significantly associated with age, level of education, marital status, or occupation but was associated with the presentation of some complications. Patients with endophthalmitis were more likely to present within 1 month (odds ratio [OR] 15.9, 95\% CI $3.9-64.9, p<0.001)$ than those who sought treatment after 1 month. Patients with secondary glaucoma were more likely to present after more than 1 year (OR 12.4, $95 \%$ CI $4.3-35.9, p<0.001)$. The median length of hospital stay was $6.3 \pm 2.9$ days.

\section{Causes, Timing, and Characteristics of Wounds}

As shown in Table 1, the most common cause of IOFBs was work-related injury $(n=926,78.7 \%)$, followed by life-related events $(n=143,12.2 \%)$ such as cooking, playing or cutting firewood, accidents such as traffic accidents or being hurt by falling/flying objects ( $n=33,2.8 \%)$, firecrackers or fireworks $(n=345,3.0 \%)$, and assaults $(n=1,0.1 \%)$. Among the patients with a known mechanism of injury, the most common was 
Table 4. Material of IOFBs among adults and children of different age-groups

\begin{tabular}{llllll}
\hline Material of IOFBs & \multicolumn{2}{l}{ Age-group } & & \multirow{2}{*}{$p$ value } \\
\cline { 2 - 4 } & $0-6, n(\%)$ & $7-12, n(\%)$ & $13-17, n(\%)$ & $\geq 18, n(\%)$ & \\
\hline Metallic & $5(20.8)$ & $6(14.3)$ & $19(70.4)$ & $846(78.0)$ & $<0.001$ \\
Stone & $4(16.7)$ & $15(35.7)$ & $2(7.4)$ & $113(10.4)$ & \\
Glass & $2(8.3)$ & $7(16.7)$ & $4(14.8)$ & $48(4.4)$ & \\
Plant & $3(12.5)$ & $4(9.5)$ & $0(0.0)$ & $24(2.2)$ & \\
Animal & $2(8.3)$ & $1(2.4)$ & $0(0.0)$ & $18(1.7)$ \\
Eyelash & $1(4.2)$ & $1(2.4)$ & $0(0.0)$ & $0(0.0)$ \\
Pencil & $5(20.8)$ & $7(16.7)$ & $0(0.0)$ & $29(2.7)$ \\
Other & $2(8.3)$ & $1(2.4)$ & $2(7.4)$ & \\
\hline
\end{tabular}

IOFBs, intraocular foreign body.

hammering metal ( $n=536,45.8 \%)$. Cutting was the second-most common mechanism of injury, accounting for $8.8 \%$. The majority of injuries occurred during spring $(n=298,26.0 \%)$ and autumn $(n=313,27.2 \%)$, but March $(n=113,9.6 \%)$ and December $(n=113,9.6 \%)$ were the individual months with the highest number of patients. February had the lowest number $(n=69,5.9 \%)$. However, the occurrence of firecracker- or fireworksassociated IOFBs in January and February was higher than in all other months, yielding a ratio of $1.7: 1$. It should be noted that the number of IOFBs caused by fireworks or firecrackers was 3.9 per year before 2016 and 2.7 per year after 2016.

Among these IOFB cases, 1,165 (99.1\%) patients were monocular IOFBs (586 right eyes were involved and 579 left eyes were involved), while 11 (0.9\%) patients suffered from bilateral IOFBs. In particular, there were 20 patients who suffered from bilateral injuries but not all of them had bilateral IOFBs. All bilateral injuries were caused by an explosion. Penetration was the most common injury $(n=1,050,88.8 \%)$, and 984 injuries were in zone I (Table 3$)$.

Characteristics of Foreign Bodies and Ocular Findings

The characteristics of the IOFBs are shown in Table 3. The objects ranged from 1 to $35 \mathrm{~mm}$ in diameter, with great variety in shapes and sizes. It was most common for the IOFBs in adults to be metal $(n=846,78.0 \%)$, followed by stone $(n=113,10.4 \%)$. For children $<7$ years old, pencils $(n=5,20.8 \%)$ and metal $(n=5,20.8 \%)$ were the most frequent IOFBs. For children age $7-12$, stones $(n=15$, $35.7 \%)$ were the most frequent IOFBs, and for adolescents, metal ( $n=19,70.4 \%)$ was the most frequent IOFB (Table 4).
Table 5. Ocular findings in eyes with IOFBs

\begin{tabular}{ll}
\hline Findings & Patients, $n(\%)$ \\
\hline Traumatic cataract & $917(78.4)$ \\
Vitreous hemorrhage & $547(46.8)$ \\
Breach of lens capsule & $396(33.9)$ \\
Retinal lesions & $361(30.9)$ \\
Endophthalmitis & $305(26.1)$ \\
Retinal breaks & $297(25.4)$ \\
Hypopyon & $187(16.0)$ \\
Hyphema & $182(15.6)$ \\
Retinal detachment & $162(13.9)$ \\
Iridodialysis & $108(9.2)$ \\
Retinal dialysis & $35(3.0)$ \\
Len subluxation & $33(2.8)$ \\
Siderosis & $32(2.7)$ \\
Secondary glaucoma & $28(2.4)$ \\
Choroid detachment & $26(2.2)$ \\
Orbital cellulitis & $18(1.5)$ \\
Cyclodialysis & $7(0.6)$ \\
\hline
\end{tabular}

Most of the IOFBs were located in the posterior segment ( $n=849,71.8 \%)$, with $521(61.4 \%)$ on the retina and $328(38.6 \%)$ in the vitreous. Of the anterior-segment IOFBs, the anterior chamber was the most common location, accounting for $32.5 \%$.

The ocular findings are shown in Table 5. Traumatic cataract ( $n=931,78.7 \%$ ) was the most frequent ocular finding, followed by vitreous hemorrhage $(n=556$, 47.1\%). Endophthalmitis was diagnosed in 197 (16.7\%) eyes. Compared with patients with anterior-segment IOFBs, the prevalence of retinal breaks or retinal detachment among patients with posterior-segment IOFBs was 5.8 times higher $(p<0.001)$. 
Table 6. Initial VA, discharge VA and OTS of eyes with IOFBs

\begin{tabular}{lc}
\hline & Eyes, $n(\%)$ \\
\hline Initial VA & \\
$\geq 20 / 40$ & $107(9.0)$ \\
$20 / 200-20 / 40$ & $159(13.5)$ \\
$1 / 200-20 / 200$ & $185(15.6)$ \\
HM/LP & $659(55.7)$ \\
NLP & $55(4.7)$ \\
Unknown & $18(1.5)$ \\
Discharge VA & \\
$\geq 20 / 40$ & $69(5.8)$ \\
$20 / 200-20 / 40$ & $114(9.6)$ \\
$1 / 200-20 / 200$ & $334(28.2)$ \\
HM/LP & $536(45.3)$ \\
NLP & $95(8.0)$ \\
Unknown & $35(3.0)$ \\
OTS & \\
$0-44$ & $407(35.4)$ \\
$45-65$ & $436(37.9)$ \\
$66-80$ & $225(19.5)$ \\
$81-91$ & $61(5.3)$ \\
$92-100$ & $22(1.9)$ \\
\hline
\end{tabular}

VA, visual acuity; OTS, ocular trauma score; HM, hand move; LP, light perception; NLP, no light perception.

Initial Visual Acuity, Visual Outcome, and Prognostic Factors Influencing Discharge Visual Acuity

Initial VA was better than or equal to 20/200 in 266 (22.5\%) patients. The VA group with the highest percentage of patients was the group with light perception/hand movement group (55.7\%). The Ocular Trauma Score (OTS) classification (Table 6) assesses the extent of the eye injury and evaluates the prognosis.

Among these patients, $98.6 \%$ agreed to surgical treatment while $1.4 \%$ refused for economic or other reasons. Of the 1,148 eyes with VA measured at discharge, 277 had increased VA of 1 or more Snellen lines, 252 had decreased VA, and 619 had no change in VA. Long-term follow-up was needed for $37.9 \%$ of patients, and $56.3 \%$ of patients needed further surgery. Permanent vision loss was reported in $5.8 \%$ of patients. Univariate and multivariate analyses of the prognostic factors influencing discharge VA are presented in Table 7 . Initial VA $<20 / 200$ (OR, $5.5 ; p<0.001$ ), wound size (OR, $1.3 ; p=0.004)$, IOFB in the posterior segment $(\mathrm{OR}, 2.6 ; p=0.002)$, and the presence of traumatic cataract $(\mathrm{OR}, 2.2 ; p=0.034)$, endophthalmitis (OR, $2.7 ; p=0.006)$, retinal detachment (OR, 3.6; $p=0.041$ ), or retinal breaks (OR, 2.4; $p=0.027$ ) were the independent risk factors for discharge VA worse than $20 / 200$.

Intraocular Foreign Bodies in Southwest China

\section{Discussion}

IOFBs are problems worldwide and represent a serious form of open-globe injuries that can result in visual loss [4]. The annual incidence rate of IOFBs in our study differed from that of a study in the UK $(0.16$ per 100,000$)$ [17]. Our study also showed a higher rate of IOFBs among all open-globe injuries than rates reported in south central China (16.2\%) [5] and Hong Kong (16\%) [6]. Differences in lifestyle, education level, income level, and government policies in different regions and countries may account for the different results across studies.

Among adults, the majority of IOFBs occurred in working-age males, consistent with most other studies [4, $5,18,19]$. Workers and farmers were the 2 most common occupations among the injured because they are more likely to have opportunities for hammering, drilling, chiseling, or shoveling, which are activities with a high risk of causing splatter of foreign bodies. And males represent the majority of laborers in China so are more prone to injuries [5]. In addition, there were a small number of patients who were hurt while watching others work. Therefore, eye protection should be enhanced for people at work, to avoid the occurrence of IOFBs. Furthermore, for patients who were injured in a traffic accident or were hurt by falling objects, we recommend increasing vigilance when in dangerous situations. In this study, patients with IOFBs were likely to have $\leq 9$ years of education, which may be related to the gradual implementation of 9-year compulsory education in China during this period (http://www.npc.gov.cn/npc/c30834/201901/21b0be5b9 7e54c5088bff17903853a0d.shtml).

For children, consistent with other studies [7, 8, 20, 21 , we found that boys were more likely to be injured. There were significant differences in sex ratio of boys and girls in different age-groups because of personality and social characteristic diversity. Preschool children $(<7$ years old), both boys and girls, lack the ability to identify risks. Thus, the protection of preschool children by parents should be increased, to reduce the incidence of IOFBs. Children in primary school (7-12 years old) have more opportunities to play with others, increasing the incidence of injury caused by others. Furthermore, the differences in hobbies between boys and girls become more obvious at this stage, with boys taking part in outdoor activities or competitive games more than girls [20, 22, 23]. Thus, the recommendations are increasing safety education, enhancing children's safety awareness and avoiding dangerous behaviors that may cause injury. Adolescents (13-17 years old) showed characteristics of both 
Table 7. Univariate and multivariate analysis of independent risk factors for discharge VA $<20 / 200$ in eyes with IOFBs

\begin{tabular}{|c|c|c|c|c|}
\hline \multirow[t]{2}{*}{ Variables } & \multicolumn{2}{|c|}{ Univariate analysis } & \multicolumn{2}{|c|}{ Multivariate analysis } \\
\hline & OR (95\% CI) & $p$ value & OR $(95 \% \mathrm{CI})$ & $p$ value \\
\hline Wound size, $\mathrm{mm}$ & $1.4(1.3,1.6)$ & $<0.001$ & $1.3(1.1,1.5)$ & 0.004 \\
\hline Wound in zone I & $1.0(0.6,1.5)$ & 0.839 & $0.8(0.3,1.9)$ & 0.606 \\
\hline IOFBs in posterior segment & $5.4(3.9,7.5)$ & $<0.001$ & $2.6(1.4,4.8)$ & 0.002 \\
\hline IOFBs size, $\mathrm{mm}$ & $1.0(1.0,1.1)$ & 0.035 & $1.0(0.9,1.0)$ & 0.643 \\
\hline Initial VA <20/200 & $12.7(8.8,18.1)$ & $<0.001$ & $5.5(2.9,10.5)$ & $<0.001$ \\
\hline Traumatic cataract & $2.6(1.9,3.7)$ & $<0.001$ & $2.2(1.1,4.6)$ & 0.034 \\
\hline Retinal detachment & $8.4(3.1,22.9)$ & $<0.001$ & $3.6(1.1,12.2)$ & 0.041 \\
\hline Endophthalmitis & $2.2(1.3,3.7)$ & 0.003 & $2.7(1.3,5.6)$ & 0.006 \\
\hline Vitreous hemorrhage & $3.1(2.2,4.4)$ & $<0.001$ & $1.1(0.6,2.0)$ & 0.786 \\
\hline Retinal breaks & $3.2(2.0,5.3)$ & $<0.001$ & $2.4(1.1,5.1)$ & 0.027 \\
\hline
\end{tabular}

IOFBs, intraocular foreign bodies; VA, visual acuity; CI, confidence interval; OR, odds ratio.

children and adults, as $59.3 \%$ of the IOFBs were workrelated and $25.9 \%$ occurred in daily life. Therefore, eye protection should be improved for adolescents.

The majority of injuries occurred during spring and autumn. A possible reason was that the temperatures were more suitable for work and farming. However, late in the year, various projects that increase workloads to achieve end-year goals, which may be responsible for the high incidence of IOFBs in December. In contrast to that, February had the lowest incidence because of the Spring Festival comes and people rest at home, leading to a low incidence of IOFB. However, during this period, there was a significantly higher occurrence of firecracker- and fireworks-associated IOFBs, which is consistent with other reports [5]. Playing with fireworks or firecrackers is an important part of the celebrations for Spring Festival. The number of firecracker- or fireworks-associated IOFBs was noticeably lower after 2016 because of the publication and promotion of the "Ban on Fireworks" that year.

The delay in presentation time was not significantly associated with patient age, level of education, marital status, or occupation in our study but was associated with the presence of certain conditions. Among patients who sought treatment $>1$ year after injury in our study, secondary glaucoma seemed to be the leading cause according to our study.

Compared with anterior-segment IOFBs, posteriorsegment IOFBs were more likely to give a worse VA, which was similar to other studies $[4,6,24]$. This was likely because IOFBs that are able to reach the posterior segment often carry more energy (to go through more tissues and reach the vitreous or retina) so can cause more damage to the eye. We also found that the IOFBs located in the vitreous tend to be accompanied by retinal lesions or breaks. Such IOFBs reach the retina first and then ricochet, finally landing in the vitreous. It seems that this kind of IOFB has a smaller size and sharper shape, leading to less resistance and less energy dissipation when going through the eyeball and along a lengthy path.

Post-traumatic endophthalmitis is a severe but uncommon complication of open-globe injury [3]. Previous studies have reported that the presence of IOFB could increase the risk of endophthalmitis [25]. Compared to other studies [3,6], our study showed a high frequency of endophthalmitis (16.7\%). Notably, our hospital is the largest medical center in Southwest China and receives the severest IOFB cases. Also, differences in injury settings in different countries may have an impact on the frequency of endophthalmitis, especially between the developed countries and developing countries.

Patients with an IOFB usually have a poor prognosis [26]. In 2002, Kuhn et al. [27] developed the OTS criteria, which is a simplified categorical system used to assess visual prognosis for ocular trauma patients. This system has now been verified by many studies $[28,29]$. In our study, about $72.1 \%$ of eyes had an initial VA grade of 1 or 2 , and $72.5 \%$ of eyes had an OTS of grade 1 or 2 . IOFBs can cause direct mechanical damage along their path, but they can also ricochet and cause additional intraocular damage [3]. Additionally, the foreign body may carry a large number of pathogens, or its own toxicity may cause damage to the eye [30].

We identified the initial VA, wound size, location of the IOFB, and the presence of certain complications (en- 
dophthalmitis, retinal detachment, retinal breaks, or traumatic cataract) as predictive factors in patients with retained IOFBs. These findings are consistent with other studies $[3,4,6,18,31]$.

In this study, we analyzed the epidemiology, clinical characteristics, and factors affecting the visual prognosis for patients with IOFBs in Southwest China. However, this study had several potential limitations. First, this study was a retrospective study in which all data were collected from medical records, and some records were not very detailed. However, there were only a small number of patients with missing data so that did not significantly affect the main findings of this study. Second, because the number of female patients was significantly lower than the number of male patients, small change in the female results could substantially affect the findings. However, we counteracted the effect of gender bias by using adjusted variables in stratified and multivariate analysis. Third, this study lacks long-term follow-up information on patients, so we cannot report the patients' final visual outcomes.

\section{Acknowledgement}

We thank Claire Barnes, $\mathrm{PhD}$, from Liwen Bianji, Edanz Editing China (www.liwenbianji.cn/ac), for editing the English text of a draft of the manuscript.

\section{Statement of Ethics}

This study was performed in line with the principles of the Declaration of Helsinki. Approval was granted by the Ethics Committee of West China Hospital (No. 2020.47). All data are anonymous and retrospectively collected, and the requirement of written informed consent was therefore waived.

\section{Conflict of Interest Statement}

The authors indicate no competing/conflicts of interest.

\section{Funding Sources}

This study was supported by the National Clinical Research Center for Geriatrics, West China Hospital, Sichuan University (no. Z2018B22), and Sichuan Province Science and Technology Support Program (CN) (no. 2018FZ0031).

\section{Author Contributions}

The study was designed by Meixia Zhang and Tiancong Chang. Material preparation, data collection, and analysis were performed by Tiancong Chang, Yun Zhang, Ling Liu, Keren Zhang, Xinyu Zhang, Miao Wang, and Yue Zeng. The manuscript was written by Tiancong Chang and Yun Zhang, reviewed and edited by Meixia Zhang. All authors read and approved the final manuscript.

\section{References}

1 Iftikhar M, Latif A, Farid UZ, Usmani B, Canner JK, Shah SMA. Changes in the incidence of eye trauma hospitalizations in the United States from 2001 through 2014. JAMA Ophthalmol. 2019;137(1):48-56.

2 Patel SN, Langer PD, Zarbin MA, Bhagat N. Diagnostic value of clinical examination and radiographic imaging in identification of intraocular foreign bodies in open globe injury. Eur J Ophthalmol. 2012;22(2):259-68.

3 Loporchio D, Mukkamala L, Gorukanti K, Zarbin M, Langer P, Bhagat N. Intraocular foreign bodies: a review. Surv Ophthalmol. 2016;61(5):582-96.

4 Zhang Y, Zhang M, Jiang C, Qiu HY. Intraocular foreign bodies in china: clinical characteristics, prognostic factors, and visual outcomes in 1,421 eyes. Am J Ophthalmol. 2011; 152(1):66-e1.

5 Wang W, Zhou Y, Zeng J, Shi M, Chen B. Epidemiology and clinical characteristics of patients hospitalized for ocular trauma in South-Central China. Acta Ophthalmol. 2017;95(6):e503-e10.

Intraocular Foreign Bodies in Southwest China
6 Liu CC, Tong JM, Li PS, Li KK. Epidemiology and clinical outcome of intraocular foreign bodies in Hong Kong: a 13-year review. Int Ophthalmol. 2017;37(1):55-61.

7 Minderhoud J, van Nispen RM, Heijthuijsen AA, Beunders VA, Bueno de Mesquita-Voigt AM, Moll AC, et al. Epidemiology and aetiology of childhood ocular trauma in the Republic of Suriname. Acta Ophthalmol. 2016; 94(5):479-84

8 Bucan K, Matas A, Lovric JM, Batistic D, Plestina Borjan I, Puljak L, et al. Epidemiology of ocular trauma in children requiring hospital admission: a 16-year retrospective cohort study. J Glob Health. 2017;7(1):010415.

9 Sahraravand A, Haavisto AK, Holopainen JM, Leivo T. Ocular traumas in working age adults in Finland: Helsinki Ocular Trauma Study. Acta Ophthalmol. 2017;95(3):288-94.

10 Sahraravand A, Haavisto AK, Holopainen JM, Leivo T. Ocular trauma in the Finnish elderly: Helsinki Ocular Trauma Study. Acta Ophthalmol. 2018;96(6):616-22.

11 Zhang T, Zhuang H, Wang K, Xu G. Clinical features and surgical outcomes of posterior segment intraocular foreign bodies in children in East China. J Ophthalmol. 2018;2018:5861043.
12 Kuhn F, Morris R, Witherspoon CD, Mester $\mathrm{V}$. The Birmingham eye trauma terminology system (BETT). J Fr Ophtalmol. 2004;27(2): 206-10.

13 Kuhn F, Morris R, Witherspoon CD. Birmingham eye trauma terminology (BETT): terminology and classification of mechanical eye injuries. Ophthalmol Clin North Am. 2002;15(2):139-43.v.

14 Gregori NZ, Feuer W, Rosenfeld PJ. Novel method for analyzing snellen visual acuity measurements. Retina. 2010;30(7):1046-50.

15 Okamoto Y, Morikawa S, Okamoto F, Mitamura Y, Ishikawa H, Ueda T, et al. Traffic accident-related open globe injuries. Retina. 2019;39(4):779-85.

16 Pieramici DJ, Sternberg P Jr, Aaberg TM Sr, Bridges WZ Jr, Capone A Jr, Cardillo JA, et al. A system for classifying mechanical injuries of the eye (globe). The Ocular Trauma Classification Group. Am J Ophthalmol. 1997; 123(6):820-31.

17 Imrie FR, Cox A, Foot B, Macewen CJ. Surveillance of intraocular foreign bodies in the UK. Eye. 2008;22(9):1141-7. 
18 Liu Y, Wang S, Li Y, Gong Q, Su G, Zhao J. Intraocular Foreign bodies: clinical characteristics and prognostic factors influencing visual outcome and globe survival in 373 eyes. J Ophthalmol. 2019;2019:5208092.

19 Wang JD, Xu L, Wang YX, You QS, Zhang JS, Jonas JB. Prevalence and incidence of ocular trauma in North China: the Beijing Eye Study. Acta Ophthalmol. 2012;90(1):e61-7.

20 Haavisto AK, Sahraravand A, Holopainen JM, Leivo T. Paediatric eye injuries in Finland: Helsinki eye trauma study. Acta Ophthalmol. 2017;95(4):392-9.

21 Cao H, Li L, Zhang M, Li H. Epidemiology of pediatric ocular trauma in the Chaoshan Region, China, 2001-2010. PLoS One. 2013; 8(4):e60844.

22 Saxena R, Sinha R, Purohit A, Dada T, Vajpayee RB, Azad RV. Pattern of pediatric ocular trauma in India. Indian J Pediatr. 2002; 69(10):863-7.
23 Puodziuviene E, Jokubauskiene G, Vieversyte $\mathrm{M}$, Asselineau K. A five-year retrospective study of the epidemiological characteristics and visual outcomes of pediatric ocular trauma. BMC Ophthalmol. 2018;18(1):10.

24 Ehlers JP, Kunimoto DY, Ittoop S, Maguire JI, Ho AC, Regillo CD. Metallic intraocular foreign bodies: characteristics, interventions, and prognostic factors for visual outcome and globe survival. Am J Ophthalmol. 2008; 146(3):427-33.

25 Dehghani AR, Rezaei L, Salam H, Mohammadi Z, Mahboubi M. Post traumatic endophthalmitis: incidence and risk factors. Glob J Health Sci. 2014;6(6):68-72.

26 Justin GA, Baker KM, Brooks DI, Ryan DS, Weichel ED, Colyer MH. Intraocular foreign body Trauma in Operation Iraqi Freedom and Operation Enduring Freedom: 2001 to 2011. Ophthalmology. 2018;125(11):167582.

27 Kuhn F, Maisiak R, Mann L, Mester V, Morris $\mathrm{R}$, Witherspoon $\mathrm{CD}$. The ocular trauma score (OTS). Ophthalmol Clin North Am. 2002; 15(2):163-vi.
28 Schorkhuber MM, Wackernagel W, Riedl R, Schneider MR, Wedrich A. Ocular trauma scores in paediatric open globe injuries. $\mathrm{Br} \mathrm{J}$ Ophthalmol. 2014;98(5):664-8.

29 Purtskhvanidze K, Rüfer F, Klettner A, Borzikowsky C, Roider J. Ocular Trauma Score as prognostic value in traumatic ocular injuries due to rotating wire brushes. Graefes Arch Clin Exp Ophthalmol. 2017;255(5): 1037-42.

30 Asencio MA, Huertas M, Carranza R, Tenias JM, Celis J, Gonzalez-del Valle F. A case-control study of post-traumatic endophthalmitis at a Spanish hospital. Int Ophthalmol. 2016; 36(2):185-94.

31 Greven CM, Engelbrecht NE, Slusher MM, Nagy SS. Intraocular foreign bodies: management, prognostic factors, and visual outcomes. Ophthalmology. 2000;107(3):608-12. 